\title{
ANALISIS KUALITAS MAKANAN KARYAWAN DI ROCKY PLAZA HOTEL PADANG
}

\author{
Aura Firstania M.S ${ }^{1}$, Lise Asnur ${ }^{2}$ \\ 1,2 Program Studi DIV Manajemen Perhotelan, Jurusan Pariwisata \\ FPP Universitas Negeri Padang, Indonesia \\ e-mail: aurafirstania@gmail.com ${ }^{1}$, lise.asnur@fpp.unp.ac.id ${ }^{2}$
}

\begin{abstract}
Abstrak
Penelitian ini berjudul Analisis Kualitas Makanan Karyawan di Rocky Plaza Hotel Padang. Tujuan dari penelitian ini adalah untuk mengetahui kualitas makanann karyawan di Rocky Plaza Hotel Padang. Kualitas makanan merupakan komponen terpenting dan utama yang harus diperhatikan, karena adanya kualitas makanan yang baik akan berdampak positif pada persepsi karyawan. Penelitian ini dilatar belakangi dengan adanya keluhan-keluhan karyawan yang menikmati makanan di kantin Rocky Plaza Hotel Padang. Adapun keluhan yang dapat ditemukan peneliti adalah salah satunya yaitu karyawan mengatakan bahwa makanan yang dihidangkan tidak variatif dari segi warna, penampilan, dan lain sebagainya. Penelitian ini merupakan penelitian deskriptif kuantitatif dengan metode survey. Jumlah sampel dalam penelitian ini adalah 91 responden. Cara pengambilan sampel dengan menggunakan teknik probability sampling. Jenis probability sampling yang digunakan adalah stratified random sampling. Data dikumpulkan menggunakan kuisioner atau angket dengan menggunakan skala likert. Teknik analisis data dilakukan dengan menggunakan program komputer SPSS versi 20.00. Hasil penelitian ini menunjukkan bahwa: Kualitas makanan berada pada kategori kurang setuju dengan nilai persentase $40,6 \%$ yang artinya kualitas makanan yang diberikan ke karyawan di Rocky Plaza Hotel Padang sudah cukup dan sesuai dengan keinginan dan harapan dari karyawan itu sendiri.
\end{abstract}

Kata kunci: Kualitas Makanan, Rocky Plaza Hotel Padang

\begin{abstract}
This research entitled Analysis of Food Quality for Employees at Rocky Plaza Hotel Padang. The purpose of this study was to determine the food quality of employees at Rocky Plaza Hotel Padang. Food quality is the most important and main component that must be considered, because good food quality will have a positive impact on employee perceptions. This research is motivated by the complaints of employees who enjoy food at the Rocky Plaza Hotel Padang canteen. The complaints that can be found by researchers is that employees say that the food served is not varied in terms of color, appearance, and so on. This research is a descriptive quantitative study with a survey method. The number of samples in this study were 91 respondents. The sampling uses probability sampling techniques. The type of probability sampling used is stratified random sampling. Data were collected using a questionnaire or questionnaire using a Likert scale. The data analysis technique was performed using the SPSS 20.00 program. The results of this study indicate that: Food quality is disagreeable category with $40.6 \%$, which means that the quality of food given to employees at Rocky Plaza Hotel Padang is sufficient and in accordance with the wishes and expectations of the employees themselves.
\end{abstract}

Keywords: Food Quality, Rocky Plaza Hotel Padang 


\section{Pendahuluan}

Industri pariwisata merupakan industri yang dikembangkan dan diandalkan sebagai salah satu sektor pendorong pertumbuhan ekonomi, karena sektor pariwisata dapat berpengaruh terhadap perekonomian masyarakat. Dalam rangka memberikan kenyamanan saat melakukan kegiatan wisata, fasilitas yang dibutuhkan oleh wisatawan yang berada jauh dari objek wisata adalah akomodasi. Salah satu akomodasi yang diminati oleh wisatawan adalah hotel.

Hotel adalah suatu perusahaan yang dikelola oleh pemiliknya dengan menyediakan pelayanan makanan, minuman dan fasilitas kamar untuk tidur kepada orang-orang yang melakukan perjalanan dan mampu membayar dengan jumlah yang wajar sesuai dengan pelayanan yang diterima tanpa perjanjian khusus

Sumatra Barat merupakan salah satu tujuan utama pariwisata Indonesia. Salah satu kota di Sumatera Barat yang memiliki daya tarik dibidang pariwisata adalah Kota Padang. Sebagai salah satu daerah destinasi wisata, kota Padang sudah melakukan berbagai upaya dalam rangka meningkatkan daya tarik wisatawan untuk berkunjung ke kota Padang. Pemerintah kota Padang menyediakan sarana dan prasana bagi setiap wisatawan yang datang. Salah satu sarana yang dibutuhkan oleh wisatawan adalah akomodasi perhotelan.

Rocky Plaza Hotel Padang adalah salah satu hotel berbintang empat ${ }^{* * * *}$ ) di Kota Padang yang berlokasi di Jalan Permindo No.40, Kp.Jao, Kecamatan Padang Barat, Kota Padang, Sumatera Barat. Hotel ini memiliki 171 kamar dengan tipe yang berbeda, 10 meeting room dan 1 ballroom yang bisa menampung 1500 orang. Letak Rocky Plaza Hotel Padang sangat strategis yaitu di pusat kota dan berdekatan dengan beberapa pusat oleh-oleh, membuat hotel ini mudah ditemui dan diminati. Rocky Plaza Hotel Padang memiliki beberapa department dalam menjalankan operasional yaitu: Food \& Beverage Service, Food \& Beverage Product, Front Office, Housekeeping, Laundry, Advertising \& Promotion, Accounting, Human Resources, Engineering dan Direksi. Total karyawan yang ada di Rocky Plaza Hotel Padang yaitu 118 orang.

Perkembangan SDM terus mengalami perubahan dari waktu ke waktu yang menyesuaikan dengan kondisi perusahaan. Karyawan merupakan aset berharga dalam suatu perusahaan (hotel). Berjalannya operasional hotel tentunya membutuhkan kualitas kerja yang baik dari karyawan. Kualitas kerja yang baik dapat diperoleh dari kesehatan yang prima, kesehatan yang prima dapat diperoleh dari kualitas makanan yang baik.

Kualitas makanan sangat berperan penting dalam memenuhi kebutuhan karyawan karena kualitas makanan akan mempengaruhi kesehatan seorang karyawan. Jika karyawan mendapatkan nutrisi yang baik maka kinerja akan meningkat tetapi jika karyawan tidak mendapatkan nutrisi yang baik maka kineja akan menurun. Hal ini berpengaruh kepada kegiatan operasional hotel. Oleh sebab itu kualitas makanan sangat dibutuhkan oleh karyawan sebagai salah satu upaya pencegahan dari berbagai penyakit di masa yang akan datang serta menjaga kondisi tubuh agar tetap produktif.

Pada dasarnya dalam menjalankan operasional hotel, sangat penting memperhatikan kualitas makanan yang diberikan terhadap karyawan. Dalam bisnis perhotelan, salah satu cara untuk memuaskan karyawan adalah dengan cara memberikan kualitas makanan yang maksimal. Rocky Plaza Hotel Padang menyediakan makan untuk karyawan sebanyak satu kali per shift. Makanan diproduksi di bagian kitchen oleh chef yang ada di Rocky Plaza Hotel Padang

Berdasarkan wawancara peneliti di lapangan pada tanggal 25 Februari 2020 kepada karyawan Human Resources di Rocky Plaza Hotel Padang, mengatakan kualitas dari makanan pada kantin Rocky Plaza Hotel Padang kurang memuaskan karyawan yang dapat diukur dengan adanya keluhan-keluhan karyawan yang menikmati makanan tersebut. Adapun keluhan yang dapat ditemukan peneliti setelah melakukan wawancara kepada karyawan HR Rocky Plaza Hotel Padang diantaranya: adanya keluhan dari karyawan yang mengatakan bahwa menu yang dihidangkan tidak variatiaf. Berdasarkan uraian permasalahan di atas, penulis mengangkat penelitian ini dengan judul "Analisis Kualitas Makanan Karyawan di Rocky Plaza Hotel Padang". 


\section{Metode}

Peneliti menggunakan jenis deskriptif kuantitatif dengan motode survey dalam melakukan penelitian yang bertujuan untuk menganalisa kualitas makanan karyawan di Rocky Plaza Hotel. Pengumpulan data dilakukan melalui angket (kuesioner) yang disusun menggunakan skala likert, terdiri dari 25 pernyataanm, dan telah teruji validitas dan reliabilitasnya. Populasinya adalah karyawan yang bekerja di Rocky Plaza Hotel Padang berjumlah 118 orang. Selanjutnya sampel diambil dengan teknik probability sampling dengan berjenis stratified random sampling, yaitu berjumlah 91 orang atau responden. Teknik analisis data dilakukan dengan menggunakan program computer SPSS versi 20.00. Data dalam penelitian ini didapatkan dengan penyebaran angket, kemudian diolah. Dengan cara menyajikan data ke dalam tabel distribusi frekuensi, menghitung nilai rata-rata Kemudian di klasifikasikan ke dalam beberapa kategori yaitu sangat setuju, setuju, kurang setuju, tidak setuju dan sangat tidak setuju.

\section{Hasil dan Pembahasan}

Tabel 1. Distribusi Frekuensi Variabel Kualitas Makanan (X)

\begin{tabular}{|c|c|c|c|}
\hline Kategori & Skor & $\mathbf{F}$ & Persentase (\%) \\
\hline Sangat Setuju & $\geq 107,25$ & 6 & $6,6 \%$ \\
\hline Setuju & $100,75-<107,25$ & 10 & $11 \%$ \\
\hline Kurang Setuju & $94,25-<100,75$ & 37 & $40,6 \%$ \\
\hline Tidak Setuju & $87,75-<94,25$ & 19 & $20,9 \%$ \\
\hline Sangat Tidak Setuju & $<87,75$ & 19 & $20,9 \%$ \\
\hline & & 91 & $100 \%$ \\
\hline
\end{tabular}

Sumber: Data Primer (Diolah), 2020

Menurut Tabel, persentase tertinggi sebesar 40,6\% ada pada rentang $94,25-<100,75$ dengan kategori kurang setuju.

Selanjutnya variabel kualitas makanan $(X)$ diklasifikasi masing-masing indikator, sebagai berikut:

Tabel 2. Distribusi Frekuensi Variabel Kualitas Makanan dari Indikator Warna

\begin{tabular}{|c|c|c|c|}
\hline Kategori & Skor & $\mathbf{F}$ & Persentase (\%) \\
\hline Sangat Setuju & $\geq 12,3$ & 12 & $13,2 \%$ \\
\hline Setuju & $11,1-<12,3$ & 35 & $38,4 \%$ \\
\hline Kurang Setuju & $9,9-<11,1$ & 41 & $45,1 \%$ \\
\hline $\begin{array}{c}\text { Tidak Setuju } \\
\text { Sangat Tidak Setuju }\end{array}$ & $\begin{array}{c}8,7-<9,9 \\
<8,7\end{array}$ & $\begin{array}{l}0 \\
3\end{array}$ & $\begin{array}{c}0 \% \\
3,3 \%\end{array}$ \\
\hline \multicolumn{2}{|c|}{ Iotal } & & $100 \%$ \\
\hline
\end{tabular}

Bersumber dari Tabel, maka persentase tertinggi sebesar $45,1 \%$ terletak pada rentang 9,9 - <11,1 dan masuk dalam kategori kurang setuju.

Tabel 3. Distribusi Frekuensi Variabel Kualitas Makanan dari Indikator Penampilan

\begin{tabular}{|c|c|c|c|}
\hline Kategori & Skor & $\mathbf{F}$ & Persentase (\%) \\
\hline Sangat Setuju & $\geq 16,95$ & 21 & $23,1 \%$ \\
\hline Setuju & $15,65-<16,95$ & 18 & $19,7 \%$ \\
\hline Kurang Setuju & $14,35-<15,65$ & 27 & $29,7 \%$ \\
\hline $\begin{array}{l}\text { Tidak Setuju } \\
\text { Sangat Tidak Setuju }\end{array}$ & $\begin{array}{c}13,05-<14,35 \\
<13,05\end{array}$ & $\begin{array}{c}5 \\
20\end{array}$ & $\begin{array}{l}5,5 \% \\
22 \%\end{array}$ \\
\hline \multicolumn{2}{|c|}{ Total } & 91 & $100 \%$ \\
\hline
\end{tabular}

Sumber: Data Primer (Diolah), 2020 
Jurnal Bosaparis: Pendidikan Kesejahteraan Keluarga

Volume 11, Nomor 1, Maret 2020

Bersumber dari Tabel, maka persentase tertinggi sebesar 29,7\% terletak pada rentang 14,35 - <15,65 dan masuk dalam kategori kurang setuju.

Tabel 4. Distribusi Frekuensi Variabel Kualitas Makanan dari Indikator Porsi

\begin{tabular}{|c|c|c|c|}
\hline Kategori & Skor & $\mathbf{F}$ & Persentase (\%) \\
\hline $\begin{array}{l}\text { Sangat Setuju } \\
\text { Setuju }\end{array}$ & $\begin{array}{c}\geq 4,75 \\
3,75-<4,75\end{array}$ & $\begin{array}{c}6 \\
69\end{array}$ & $\begin{array}{c}6,6 \% \\
75,8 \%\end{array}$ \\
\hline Kurang Setuju & $3,25-<3,75$ & 0 & $0 \%$ \\
\hline $\begin{array}{c}\text { Tidak Setuju } \\
\text { Sangat Tidak Setuju }\end{array}$ & $\begin{array}{c}2,75-<3,25 \\
<2,75\end{array}$ & $\begin{array}{c}13 \\
3\end{array}$ & $\begin{array}{c}14,3 \% \\
3,3 \%\end{array}$ \\
\hline \multicolumn{2}{|c|}{ Total } & 91 & $100 \%$ \\
\hline
\end{tabular}

Sumber: Data Primer (Diolah), 2020

Bersumber dari Tabel, makapersentase tertinggi sebesar 75,8\% terletak pada rentang 3,75 - $<4,75$ dan masuk dalam kategori setuju.

Tabel 5. Distribusi Frekuensi Variabel Kualitas Makanan dari Indikator Bentuk

\begin{tabular}{|c|c|c|c|}
\hline Kategori & Skor & $\mathbf{F}$ & Persentase (\%) \\
\hline Sangat Setuju & $\geq 8,05$ & 17 & $18,7 \%$ \\
\hline Setuju & $7,35-<8,05$ & 35 & $38,5 \%$ \\
\hline Kurang Setuju & $6,65-<7,35$ & 28 & $30,7 \%$ \\
\hline Tidak Setuju & $5,95-<6,65$ & 4 & $4,4 \%$ \\
\hline Sangat Tidak Setuju & $<5,95$ & 7 & $7,7 \%$ \\
\hline Total & & 91 & $100 \%$ \\
\hline
\end{tabular}

Bersumber dari Tabel, maka persentase tertinggi sebesar 38,5\% terletak pada rentang 7,35 - <8,05 dan masuk dalam kategori setuju.

Tabel 6. Distribusi Frekuensi Variabel Kualitas Makanan dari Indikator Temperatur

\begin{tabular}{cccc}
\hline Kategori & Skor & F & Persentase (\%) \\
\hline Sangat Setuju & $\geq 9,05$ & 2 & $2,2 \%$ \\
Setuju & $8,35-<9,05$ & 36 & $39,6 \%$ \\
Kurang Setuju & $7,65-<8,35$ & 22 & $24,2 \%$ \\
Tidak Setuju & $6,95-<7,65$ & 27 & $29,6 \%$ \\
Sangat Tidak Setuju & $<6,96$ & 4 & $4,4 \%$ \\
\hline & & $\mathbf{9 1}$ & $\mathbf{1 0 0 \%}$
\end{tabular}

Sumber: Data Primer (Diolah), 2020

Bersumber dari Tabel, maka persentase tertinggi sebesar 39,6\% terletak pada rentang 8,35 - <9,05 dan masuk dalam kategori setuju.

Tabel 7. Distribusi Frekuensi Variabel Kualitas Makanan dari Indikator Tekstur

\begin{tabular}{|c|c|c|c|}
\hline Kategori & Skor & $\mathbf{F}$ & Persentase (\%) \\
\hline Sangat Setuju & $\geq 12,7$ & 11 & $12,1 \%$ \\
\hline Setuju & $11,9-<12,7$ & 13 & $14,3 \%$ \\
\hline Kurang Setuju & $11,1-<11,9$ & 0 & $0 \%$ \\
\hline Tidak Setuju & $10,3-<11,1$ & 44 & $48,3 \%$ \\
\hline Sangat Tidak Setuju & $<10,3$ & 23 & $25,3 \%$ \\
\hline \multicolumn{2}{|c|}{ Total } & 91 & $100 \%$ \\
\hline
\end{tabular}

Sumber: Data Primer (Diolah), 2020

Bersumber dari Tabel, maka persentase tertinggi sebesar 48,3\% terletak pada rentang 10,3 - <11,1 dan masuk dalam kategori tidak setuju. 
Jurnal Bosaparis: Pendidikan Kesejahteraan Keluarga

Volume 11, Nomor 1, Maret 2020

Tabel 8. Distribusi Frekuensi Variabel Kualitas Makanan dari Indikator Rasa

\begin{tabular}{|c|c|c|c|}
\hline Kategori & Skor & $\mathbf{F}$ & Persentase (\%) \\
\hline Sangat Setuju & $\geq 22$ & 20 & $22 \%$ \\
\hline Setuju & $20-<22$ & 21 & $23,1 \%$ \\
\hline Kurang Setuju & $18-<20$ & 27 & $29,7 \%$ \\
\hline Tidak Setuju & $16-<18$ & 11 & $12,1 \%$ \\
\hline Sangat Tidak Setuju & $<16$ & 12 & $13,1 \%$ \\
\hline Total & & 91 & $100 \%$ \\
\hline
\end{tabular}

Bersumber dari Tabel, maka persentase tertinggi sebesar 29,7\% terletak pada rentang 18 - <20 dan masuk dalam kategori kurang setuju

Tabel 9. Distribusi Frekuensi Variabel Kualitas Makanan dari Indikator Aroma

\begin{tabular}{|c|c|c|c|}
\hline Kategori & Skor & $\mathbf{F}$ & Persentase (\%) \\
\hline Sangat Setuju & $\geq 13,5$ & 7 & $7,7 \%$ \\
\hline Setuju & $12,5-<13,5$ & 10 & $11 \%$ \\
\hline Kurang Setuju & $11,5-<12,5$ & 44 & $48,3 \%$ \\
\hline Tidak Setuju & $10,5-<11,5$ & 21 & $23,1 \%$ \\
\hline Sangat Tidak Setuju & $<10,5$ & 9 & $9,9 \%$ \\
\hline Total & & 91 & $100 \%$ \\
\hline
\end{tabular}

Bersumber dari Tabel, maka persentase tertinggi sebesar 48,3\% terletak pada rentang 11,5 - $<12,5$ dan masuk dalam kategori kurang setuju.

Tabel 10. Distribusi Frekuensi Variabel Kualitas Makanan Dari Indikator Tingkat Kematangan

\begin{tabular}{|c|c|c|c|}
\hline Kategori & Skor & $\mathbf{F}$ & Persentase (\%) \\
\hline Sangat Setuju & $\geq 8,7$ & 9 & $9,9 \%$ \\
\hline Setuju & $7,9-<8,7$ & 38 & $41,7 \%$ \\
\hline Kurang Setuju & $7,1-<7,9$ & 0 & $0 \%$ \\
\hline Tidak Setuju & $6,3-<7,1$ & 24 & $26,4 \%$ \\
\hline Sangat Tidak Setuju & $<6,3$ & 20 & $22 \%$ \\
\hline \multicolumn{2}{|c|}{ Total } & 91 & $100 \%$ \\
\hline
\end{tabular}

Sumber: Data Primer (Diolah), 2020

Bersumber dari tabel, maka persentase tertinggi sebesar $41,7 \%$ terletak pada rentang 7,9 - <8,7 dan masuk dalam kategori setuju.

Bersumberkan uraian yang dikemukakan diatas, maka dapat diketahui bahwa analisis kualitas makanan karyawan di Rocky Plaza Hotel Padang yang dilakukan terhadap 91 responden menunjukkan bahwa variabel kualitas makanan dikategorikan kurang setuju dengan persentase sebesar 40,6\% terletak pada rentang 94,25 - <100,75. Dapat disimpulkan kualitas makanan karyawan di Rocky Plaza Hotel Padang masuk kedalam kategori kurang baik. Sesuai dengan pendapat Menurut Dita (2010: 10) kualitas produk makanan memiliki pengaruh terhadap kepuasan konsumen, sehingga akan lebih baik bila dapat meningkatkan dan mempertahankan kualitas prosuk makanan sebagai dasar strategi pemasaran.

\section{Simpulan dan Saran}

Tujuan Secara keseluruhan Kualitas Makanan Karyawan di Rocky Plaza Hotel Padang berada pada kategori kurang setuju dengan persentase $40,6 \%$ dan berada pada rentang skor $94,25 \leq 100,75$. Sedangkan berdasarkan indikator dapat dilihat berikut ini: 1) Warna tergolong pada pada kategori kurang setuju dengan persentase sebesar $45,1 \%$ berada pada rentang skor $9,9 \leq 11,1$; 2) Penampilan tergolong pada kategori kurang setuju dengan persentase sebesar $29,7 \%$ berada pada rentang skor $14,35 \leq 15,65 ; 3)$ Porsi tergolong pada kategori setuju dengan persentase sebesar $75,8 \%$ berada pada rentang skor $3,75 \leq 4,75 ; 4)$ Bentuk tergolong pada pada kategori setuju dengan persentase sebesar $38,5 \%$ berada pada rentang skor $7,35 \leq 8,05$; 
Jurnal Bosaparis: Pendidikan Kesejahteraan Keluarga

Volume 11, Nomor 1, Maret 2020

5) Temperatur tergolong pada kategori setuju dengan persentase sebesar 39,6\% berada pada rentang skor $8,35 \leq 9,05$; 6) Tekstur tergolong pada kategori tidak setuju dengan persentase sebesar $48,3 \%$ berada pada rentang skor $10,3 \leq 11,1 ; 7)$ Rasa tergolong pada pada kategori kurang setuju dengan persentase sebesar $29,7 \%$ berada pada rentang skor $18 \leq 20$; 8) Aroma tergolong pada kategori kurang setuju dengan persentase sebesar $48,3 \%$ berada pada rentang skor $11,5 \leq 12,5$

Tingkat kematangan tergolong pada kategori setuju dengan persentase sebesar $41,7 \%$ berada pada rentang skor $7,9 \leq 8,7$

\section{Daftar Pustaka}

Agus, Sulastiyono. (2011). Manajemen Penyelanggaraan Hotel. Bandung: Alfabeta.

Dita. 2010. "Pengaruh Harga dan kualitas produk terhadap kepuasan pelanggan pada Majestyk Backry \& Cake Shop Cabang H.M Yamin Medan". Jurnal Pendidikan Ekonomi. Vol. 2 No.1

Margaretha, S Fiani dan Edwin japarianto. 2012. "Analisa pengaruh Food Quality \& brand image terhadap keputusan pembelian roti kecik toko roti ganep's di kota Solo". Jurnal Manajemen Pemasaran. Vol. 4 No. 2.

Sugiyono. 2018. Metode penelitian Kuantitatif. Bandung: Alfabeta

Sugiyono. 2011. Metode Penelitian Kuantitatif, Kualitatif dan R\&D. Bandung: Afabeta 